\title{
INFLUENCE OF THE SAND PARTICLE SIZE ON THE BOND OF CEMENT MATRIX-ALKALI TREATED JUTE FIBERS
}

\author{
Yasmim Gabriela dos Santos Mendonça ${ }^{1 *}$, Bartosz Zukowski ${ }^{2}$, Romildo Dias Toledo \\ Filho $^{3}$ \\ $1^{*}, 2,3$ Department of Civil Engineering, COPPE, Universidade Federal do Rio de \\ Janeiro, P.O. Box 68506, 21941-972, Rio de Janeiro, RJ, Brazil; \\ 1* yasmim.mend1@gmail.com, ${ }^{2}$ bzukowski87@gmail.com, ${ }^{3}$ \\ rdtoledofilho@gmail.com; ${ }^{1 *}, 2,3$ Universidade Federal do Rio de Janeiro.
}

\begin{abstract}
This work presents the influence of the sand particle size on the cementitious matrix bond for alkali treated jute fibers. The fibers were washed for 3 hours in water at 80 ${ }^{\circ} \mathrm{C}$, then cooled at $40{ }^{\circ} \mathrm{C}$ for 5 hours. This process was applied to remove residues and impurities from the fiber's surface. After washing and cooling, the fibers were additionally submerged in a saturated solution of calcium hydroxide, $\mathrm{Ca}(\mathrm{OH})_{2}$ for 50 minutes and then were dried for 24 hours at $40{ }^{\circ} \mathrm{C}$. The tensile stress-strain behavior of the fibers was determined at a microforce testing system using the gage length of 20 $\mathrm{mm}$. The cross-sectional area of the fiber was measured using a scanning electron microscope (SEM) micrographs and image analysis. The Young's modulus, force at rupture, maximum stress and strain were calculated from the collected data to evaluate the influence of alkaline treatment on fiber's tensile properties. To evaluate the effect of the maximum particle size of the sand on the fiber-matrix bond, pull-out tests were performed for fiber embedment length of $7 \mathrm{~mm}$ with three different matrices related to maximum particle sizes of 250,425 and $710 \mu \mathrm{m}$, respectively. The results showed that the matrix with the highest maximum particle size of sand presented higher fibermatrix bond than the other ones.
\end{abstract}

Keywords: particle size of sand, jute, fiber-matrix bond, pull-out tests. 


\section{INTRODUCTION}

Jute is a name of a fiber extracted from the plants in the genus Corchorus, from family Tiliaceae. About forty different species are known among Corchorus family, but just the C.capsularis (popularly known for "white jute") and C.olitorius are cultivated on a commercial scale [1]. Jute fibers are largely used in all the world mostly as packaging material, floor covering, insulation material, soil protection, handicrafts, among others [2]. Jute cultivation is predominantly annual. The cultivation process is laborious but requires relatively small amounts of fertilizers and pesticides. It can be carried out on small land. For these reasons, the production of jute is more concentrated in Bangladesh, India, Nepal, China, and Thailand than in other places. These countries correspond about $95 \%$ of the world production. India is the biggest producer and consumer of jute in the world. Bangladesh is the second biggest producer and the main exporter of fibers [3]. From the 1930's to the beginning of 1990 the production of fibers was dominant along the Amazon River, between Manaus and Santarem, in the region of lowlands. Japanese immigrants introduced the culture in the region to supply the demand for jute bags in southern Brazil, where the bags were used to the packaging of commodities, mainly the coffee. Changes in the packaging of goods, quality of the fiber, removal of tariffs on imported jute, contributed to jute market collapse in the 1990's. Despite this, the legacy of jute is still evident in the physical and social landscape of the region [4].

The mechanical properties of natural fibers present a lot of variation and depend on some factors: diameter of the fiber, structure, degree of polymerization, crystalline structure, origin (stem, leaf, fruit, and seed) and growth conditions [5]. The area of jute is smaller than the area of some other fibers as sisal or curauá. The tensile strength of the jute $(249 \mathrm{MPa})$ is less than curauá (543 MPa) and sisal (484 MPa), but Young's modulus is not so distant from it, 43,9, 19,5 and 63,7 GPa to jute, sisal and curauá, respectively [6]. The physical and mechanical properties of the fibers are influenced by their composition, mainly cellulose, hemicelluloses, and lignin. Fiber treatments can promote a better interaction between lignin, cellulose, and hemicellulose, resulting in a stronger fiber, with a higher crystallinity and modulus. The natural fibers tensile strength increase with the application of hornification treatments, because of the change in the cellulose crystallinity and possible bonds created between different polymer chains in the microfibrils. Alkaline treatment promotes changing in cellulose chemical bonds, as well as the reduction of fiber-water absorption capacity. The jute is the fiber that presents a higher interaction with the calcium hydroxide. Jute contains cellulose of high crystallinity, which collaborates well with $\mathrm{Ca}(\mathrm{OH})_{2}$ [7]. It is reported in the literature that the alkaline treatment improved the interaction between jute fibers and cementitious matrix, providing a better frictional phase [7].

Matrices of strain hardening cementitious composite (SHCC) have bigger cement content than the conventional matrices and this is justified because this binder contributes to the control of composite rheology and improve the dispersion of the fibers [8]. Moreover, this also contributes to the control of matrix tenacity, one of the main criteria that characterize the composite with strain hardening behavior [8]. Not all type of aggregate is favorable in the production of SHCC. One of the common 
aspects in this type of matrix is the absence of large aggregates, since its presence in the matrix imposes a heterogeneity responsible for the generation of fragile failure mechanisms, contrary to the ductility principles characteristic of SHCC [8]. This work

presents the results of the study of stress-strain behavior and fiber-matrix bond of treated jute fibers and matrices with the different maximum size of sand as a preliminary study of jute fiber - cement matrix interaction for future SHCC design.

\section{MATERIALS AND METHODS}

\section{Jute fiber and treatment applied}

The jute fiber is extracted from the plant stem in a process based on the following steps: cutting, hardening, crushing, drying and classification [6]. The chemical composition of jute fiber was verified on two sets of samples at the COPPE/UFRJ by calorimetric determination of hexuronic acids. The percentage values showed the amount of cellulose $74.4 \%$, hemicellulose $15.0 \%$, lignin $8.4 \%$. The fibers were first washed in water at $80{ }^{\circ} \mathrm{C}$ for 3 hours to remove residues and impurities. Then they were cooled at $40^{\circ} \mathrm{C}$ for 5 hours. After the washing process, the fibers the fibers were combed and then cut in a guillotine. After the fibers combing, the fibers were separated into two groups, namely untreated and alkaline. The untreated group was not submitted for treatment and for this reason this group was considered the reference group. The alkaline group was submerged in a saturated solution of $\mathrm{Ca}(\mathrm{OH})_{2}$ with water for 50 minutes, and then dried for 24 hours at the temperature of $40{ }^{\circ} \mathrm{C}$. It was made Thermal Analysis of the jute fiber before and after the treatment applied. The weight lost, between $250{ }^{\circ} \mathrm{C}$ and $350{ }^{\circ} \mathrm{C}$, corresponds to the hemicellulose decomposition [9]. Therefore, the results (Figure 1) showed that the alkaline treatment reduced the amount of hemicellulose contend present on the fiber, because the thermal peak between 250 ${ }^{\circ} \mathrm{C}$ and $350{ }^{\circ} \mathrm{C}$, corresponding to the weight lost, is bigger to the fiber without treatment than to the treated fiber. 


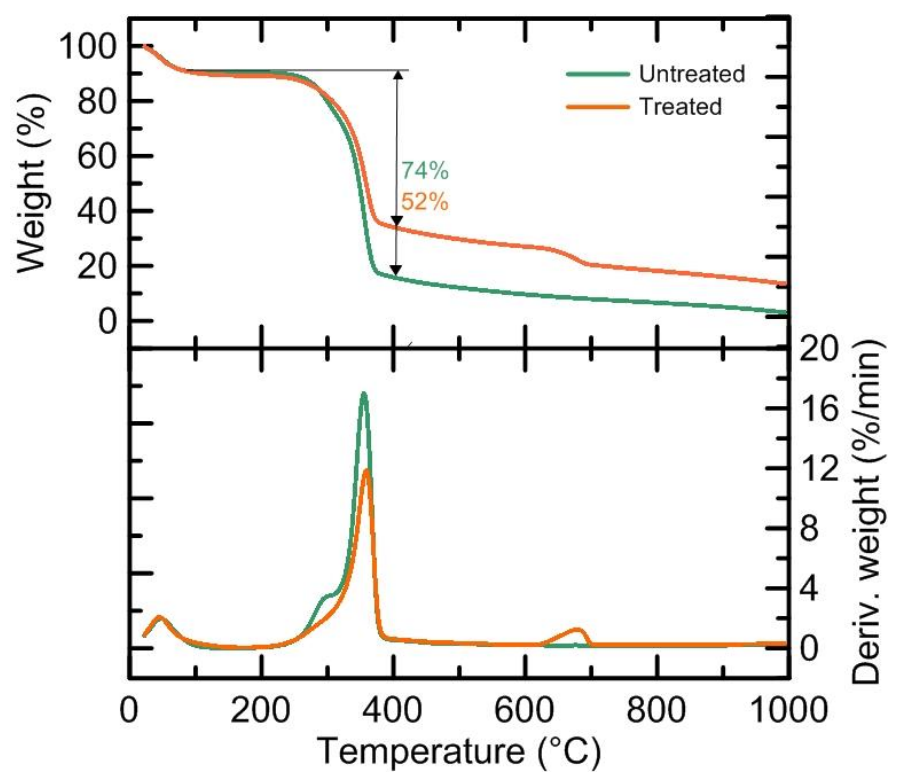

Figure 1: Thermal analysis of the fibers before and after the treatment.

\section{Fiber Microstructural Analysis}

The fiber's microstructure was investigated using a SEM (TM 3000) at $15 \mathrm{kV}$ of accelerating voltage. The images obtained were processed using the software package ImageJ for measuring the cross-section of each fiber. A contour line was interactively drawn to delineate the fiber's cross-section and then the area was measured, as illustrate the Figure 2.a. The visual analysis of fiber surface (Figure 2.b and c) was carried at SEM. To analyze the surface of the fibers they were covered with an approximately $20 \mathrm{~nm}$ layer of gold before the visual investigation under the microscope. It was applied an X-ray microanalysis technique, namely Energy Dispersion Spectroscopy (EDS), to determinate the chemical composition of the elements on the surface of the fibers. The chemical composition maps obtained in the EDS showed that the alkaline treatment caused the formation of calcium hydroxide crystals, which was proved by the presence of calcium on the surface of the fiber (Figure 4).

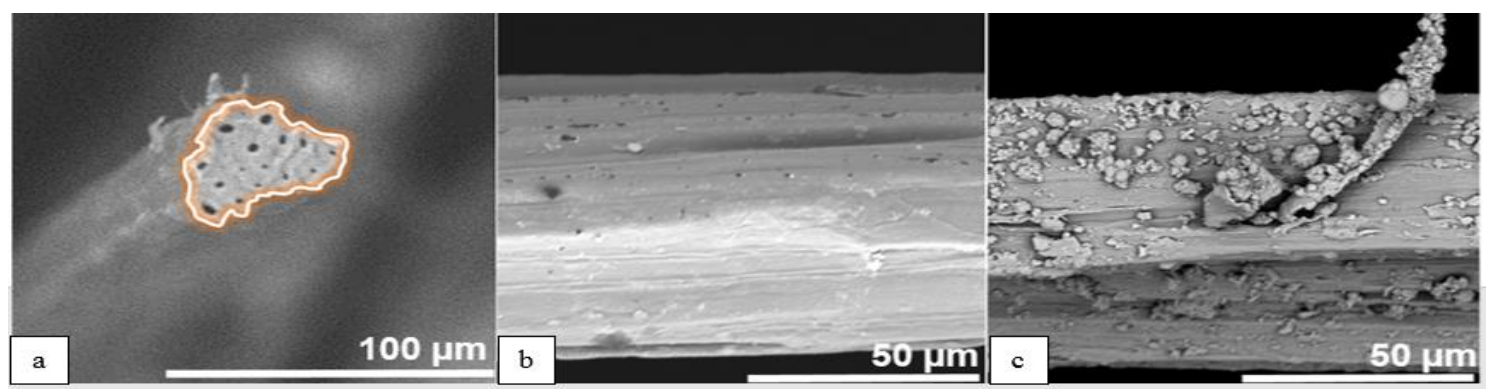

Figure 2: Micrographs of jute fibers at SEM: (a) area calculation using ImageJ, (b) surface of untreated jute fiber, (c) surface of alkaline treated jute fiber. 

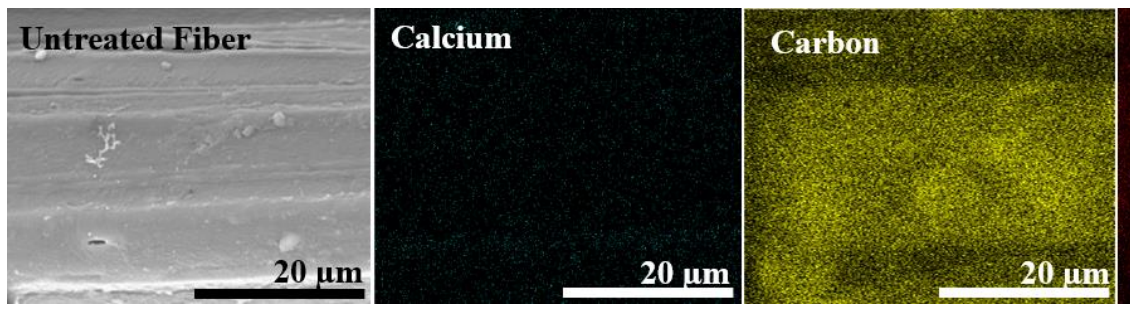

\section{Oxygen}

Figure 3: Chemical composition maps of elements on the untreated fiber surface obtained in the EDS .

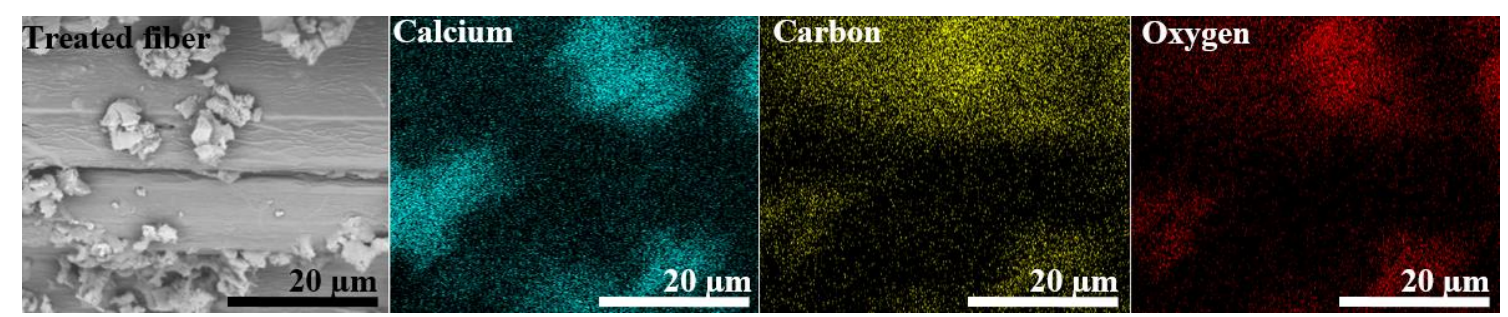

Figure 4: Chemical composition maps of elements on the treated fiber surface obtained in the EDS .

\section{Fiber Tensile Test}

The jute fibers were investigated at the gage length of $20 \mathrm{~mm}$. The groups untreated and alkaline were tested. Before the test fibers were dried for 24 hours at $40{ }^{\circ} \mathrm{C}$. The preparation of the test was performed according to ASTM C1557 [10]. The tensile tests were performed in a microforce testing machine Tytron 250 (Figure 5) at the strain rate of $0.1 \mathrm{~mm} / \mathrm{min}$.
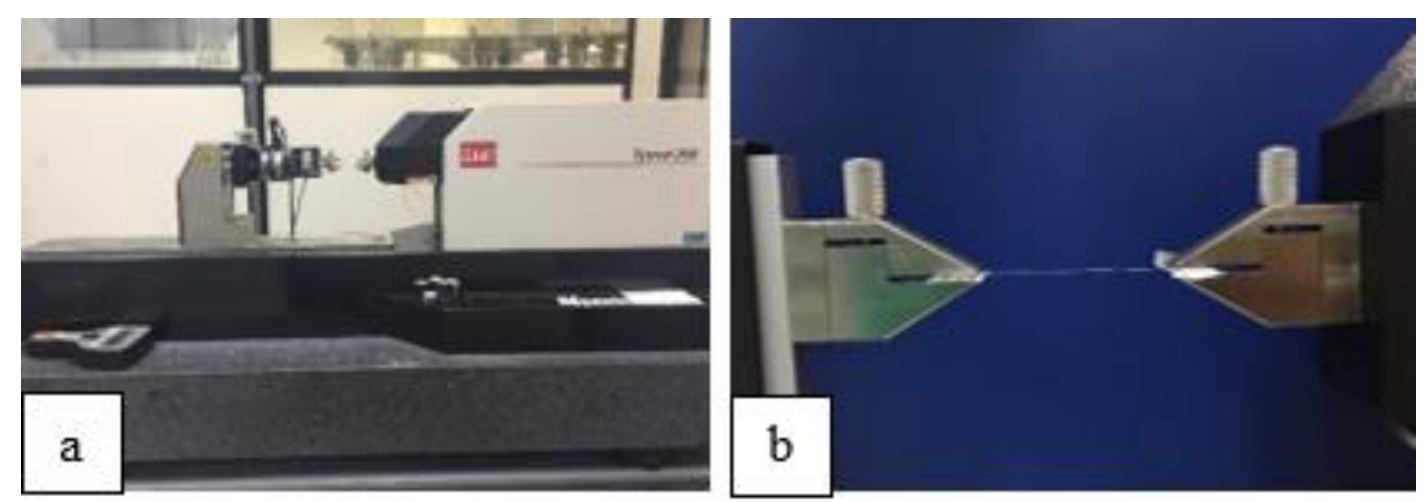

Figure 5: Setup of the tensile test according to ASTM C1557: (a) machine Tytron 250, (b) detail of clamps and specimen. 


\section{Cementitious Matrix Composition}

It was produced three matrices with the same composition but with different sand particle size. The matrices were composed by $33 \%$ of cement Portland CPII F-32, 27\% of metakaolin, $40 \%$ of fly ash, sand, water, superplasticizer (SP) Glenium 51, and viscosity agent (VMA), in a proportion of 1:0.5:0.4 (cementitious materials: sand: water/cementitious materials). The matrices were namely according the size of the maximum particle size of the sand. M250, M425 and M710 are the name of the matrices produced with the sand that have the maximum particle size of 250, 425 and $710 \mu \mathrm{m}$, respectively. The granulometry curves of the cementitious materials and of the sands used in this study are presented in the Figure 6.
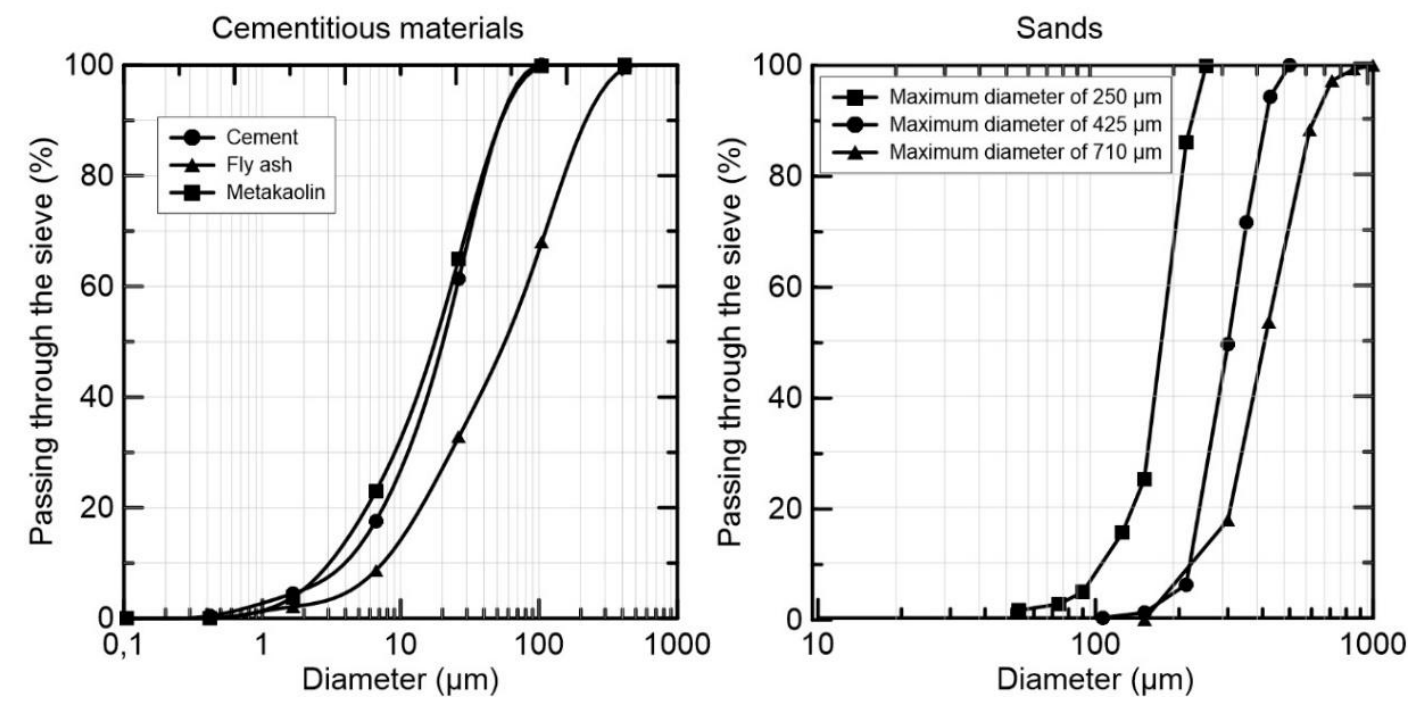

Figure 6: Granulometry curves of cementitious materials (left) and sands (right).

The composition to produce $1 \mathrm{~m}^{3}$ of matrix is presented in the Table 1 . In addition, to evaluate if the cementitious matrices were free of calcium hydroxide, it was made Thermal Analysis of the cementitious paste composed of water and cementitious materials for the ages of 28,60 and 90 days. The results (Figure 7) showed that the matrices produced had just low contend of calcium hydroxide, about $0,3 \%$ of $\mathrm{Ca}(\mathrm{OH})_{2}$, because the weight loss at temperatures near to $400^{\circ} \mathrm{C}$ for the ages of 28,60 and 90 days were $0,22 \%, 0,32 \%$ and $0,24 \%$. The temperature of $400^{\circ} \mathrm{C}$ is justified because it is characterized by the dihydroxylation of the calcium hydroxide according to the literature [11]. 
Table 1: Matrix composition for $1 \mathrm{~m}^{3}$.

\begin{tabular}{c|c}
\hline \multicolumn{2}{l}{$\begin{array}{c}\text { Cementitious matrix } \\
\text { composition }\left(\mathbf{K g} / \mathbf{m}^{3}\right)\end{array}$} \\
\hline Cement & 364,08 \\
\hline Fly ash & 436,90 \\
\hline Metakaolin & 291,26 \\
\hline Sand & 546,11 \\
\hline Water & 419,09 \\
\hline SP & 25,99 \\
\hline VMA & 0,87 \\
\hline
\end{tabular}

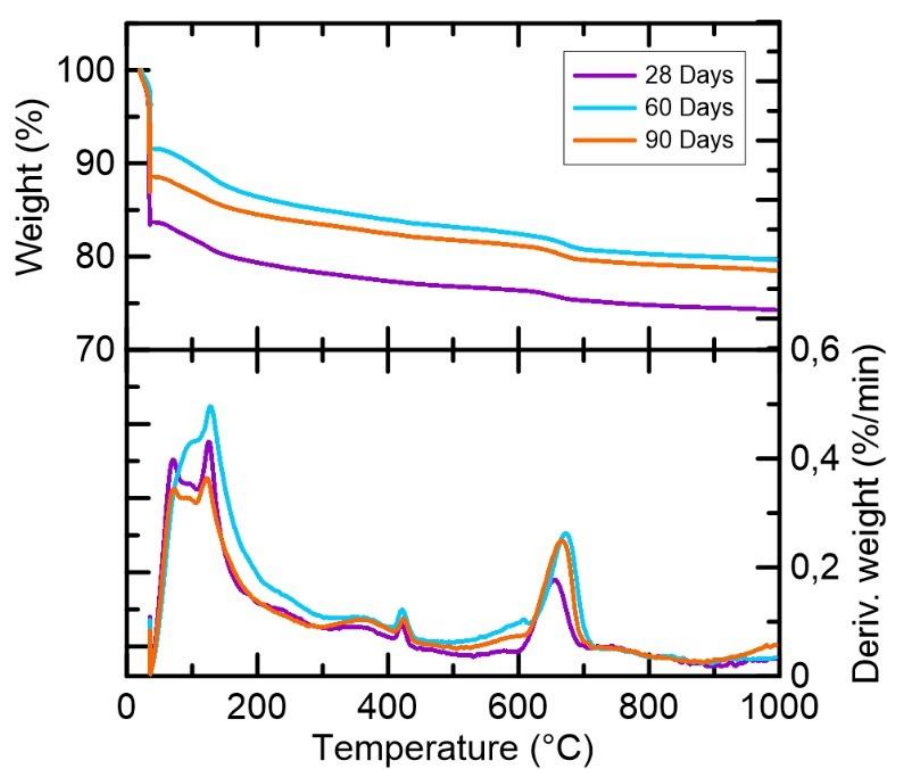

Figure 7: Thermal analysis of the cementitious paste.

\section{Fiber-Matrix Bond}

Verification of the fiber-matrix interface was performed through pull-out tests to the fibers submitted to the alkaline treatment. To ensure an adequate coating of the fiber in the matrix, PVC molds were used. The PVC mold is a tube with a depth of $7 \mathrm{~mm}$ corresponding to the fiber embedment length and $25 \mathrm{~mm}$ of diameter.

The matrix was poured inside the PVC mold, and the paper tape closed the specimen providing the straight and central position of the fiber in the mold. After 27 days of curing in a room of $100 \% \mathrm{RH}$ and $21 \pm 1{ }^{\circ} \mathrm{C}$ additional 1 day of drying at $23 \pm 1{ }^{\circ} \mathrm{C}$, to provide conditions similar to composite's curing, the fibers were tested to verify pull-out behavior in microforce machine Tytron 250 at the strain rate of $0.1 \mathrm{~mm} / \mathrm{min}$ with $50 \mathrm{~N}$ load cell.

The pull-out test starts with the tube placed in the iron ring and clenched by screws to prevent specimen's movement during the test. The fiber is pulled out from the specimen (Figure 8) and Tytron 250 collects the data of force and displacement.

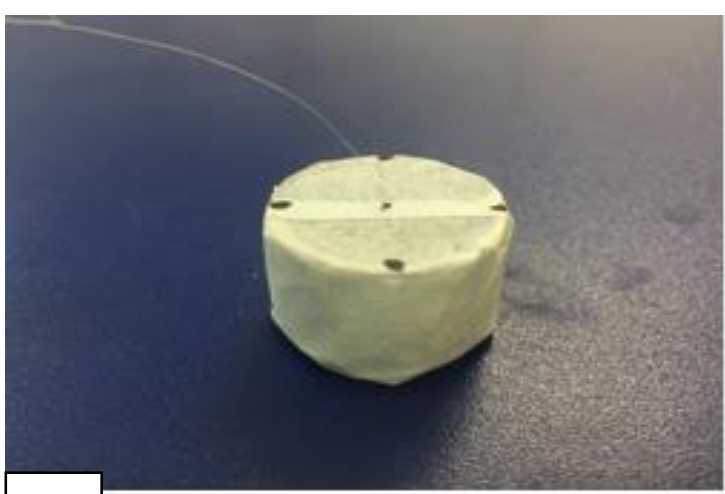

(a)

Figure 8: Pull-out test: (a) specimen

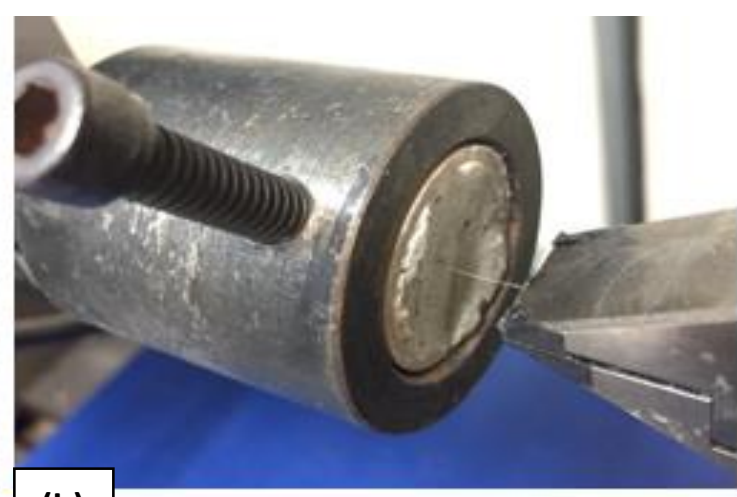

(b) aration, (b) completed test. 
Then the collected data was analyzed and the values of chemical debonding energy $\left(\mathrm{G}_{\mathrm{d}}\right)$ and the maximum bond strength $\left(\tau_{\max }\right)$ were calculated. To calculate $\mathrm{G}_{\mathrm{d}}$ it was calculate the area (AREA 1) under the force versus displacement curve and then this area was divide for the product of the embedment length $\left(l_{f}\right)$ and the perimeter of the curve. The Figure 9 illustrates the pull-out test behaviour and the way to calculate $\mathrm{G}_{\mathrm{d}}$. The $\tau_{\max }$ were calculated by Equation 1 .

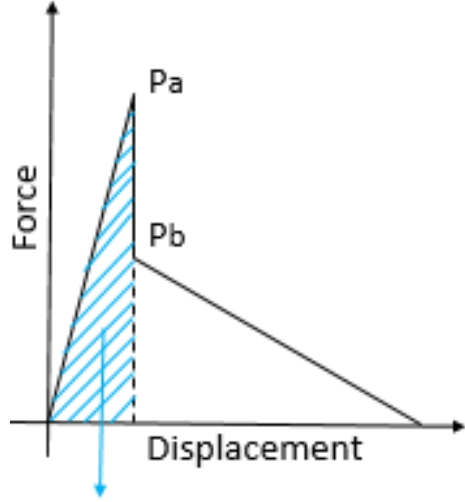

AREA 1

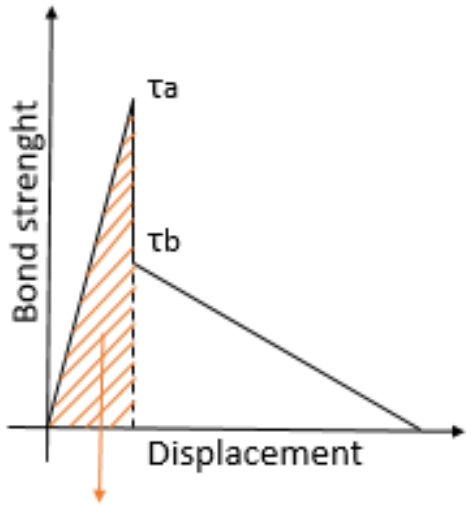

$\mathrm{Gd}=\operatorname{AREA} 2=\frac{\text { AREA } 1}{l_{f} \text { Perimeter }}$

Figure 9: Pull-out behaviour and the Gd área.

$\tau_{\max }=\frac{P_{\max }}{l_{f} \text { Perimeter }}$

Where $\mathrm{P}_{a}$ is the peak load of single fiber pull-out curve, $\mathrm{P}_{b}$ is the load after sudden drop fallowing $\mathrm{P}_{\mathrm{a}}$, Perimeter is the perimeter measured in the same software, $P_{\max }$ is the maximum force in the frictional region, and $l_{\mathrm{f}}$ is the embedment length.

\section{RESULTS AND DISCUSSION}

\section{- Fiber Tensile Test}

In Table 2 and in Figure 10 are presented the results of the tensile test of jute fibers for the two groups (untreated and alkaline). It is possible to note that the alkaline treatment reduced the area of the fibers in comparison to the untreated group, and the treated fibers presented higher tensile strength values than untreated fibers. Moreover, the alkaline treatment increased the value of the elastic modulus. The untreated jute fiber ruptured at $0.89 \mathrm{~N}(0.35)$ when the alkaline treated fibers ruptured at $1.37 \mathrm{~N}(0.15)$. The higher value of force at rupture of treated fibers was followed by the higher tensile strength $689 \mathrm{MPa}(74)$ versus $244 \mathrm{MPa}(95)$ for untreated fiber. The increased value of strength was also a result of the area difference $3660 \mu \mathrm{m}^{2}$ (570) for untreated fibers versus $1990 \mu \mathrm{m}^{2}$ (500) for alkaline treated fibers. Due to improved mechanical 
properties of jute fibers after alkaline treatment, the pull-out tests were carried on treated fibers.

Table 2: Summary of average tensile test results and standard deviation for untreated jute fibers and alkaline jute fibers.

\begin{tabular}{|c|c|c|c|c|c|c|c|c|}
\hline \multirow[b]{2}{*}{ Jute fiber } & \multirow{2}{*}{$\begin{array}{c}\mathbf{N}^{\circ} \\
\text { specimens }\end{array}$} & \multirow{2}{*}{$\begin{array}{l}\text { Area } \\
\left(\mu \mathbf{m}^{2}\right)\end{array}$} & \multicolumn{2}{|c|}{ Diameter } & \multirow{2}{*}{$\begin{array}{c}\text { Strain } \\
\text { to } \\
\text { failure } \\
(\%)\end{array}$} & \multirow{2}{*}{$\begin{array}{c}\text { Force } \\
\text { at } \\
\text { rupture } \\
(\mathbf{N})\end{array}$} & \multirow{2}{*}{$\begin{array}{c}\text { Tensile } \\
\text { strength } \\
(\mathbf{M P a})\end{array}$} & \multirow{2}{*}{$\begin{array}{l}\text { Young's } \\
\text { modulus } \\
(\text { GPa })\end{array}$} \\
\hline & & & $\begin{array}{r}\text { Major } \\
(\mu\end{array}$ & Minor & & & & \\
\hline Untreated & 11 & $\begin{array}{l}3660 \\
(570)\end{array}$ & $\begin{array}{c}95 \\
(20)\end{array}$ & $\begin{array}{l}50 \\
(9)\end{array}$ & $\begin{array}{c}1.06 \\
(0.40)\end{array}$ & $\begin{array}{c}0.89 \\
(0.35)\end{array}$ & $\begin{array}{l}244 \\
(95)\end{array}$ & $\begin{array}{l}22 \\
(7)\end{array}$ \\
\hline Alkaline & 7 & $\begin{array}{l}1990 \\
(500)\end{array}$ & $\begin{array}{c}74 \\
(14)\end{array}$ & $\begin{array}{c}34 \\
(10)\end{array}$ & $\begin{array}{c}2.06 \\
(0.77)\end{array}$ & $\begin{array}{c}1.37 \\
(0.15)\end{array}$ & $\begin{array}{l}689 \\
(74)\end{array}$ & $\begin{array}{c}35 \\
(10)\end{array}$ \\
\hline
\end{tabular}

*Parenthesis number: standard deviation.
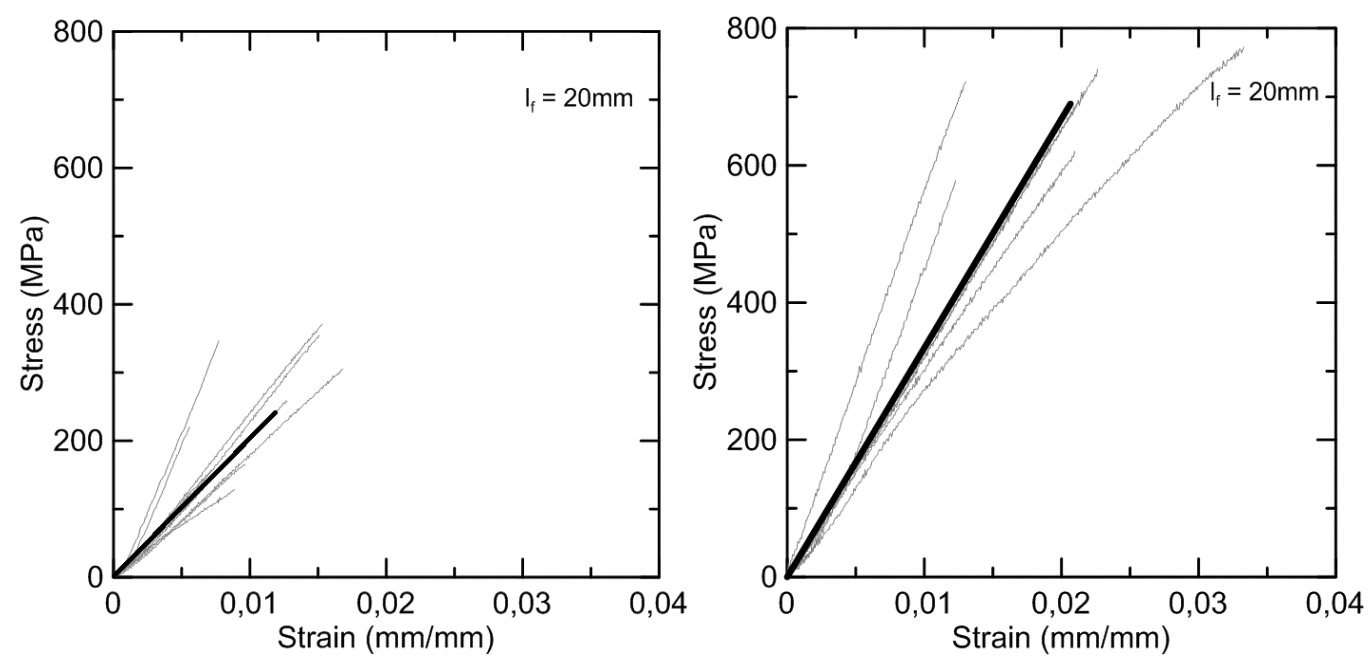

Figure 10: Tensile test results for untreated jute fibers (left) and for alkaline jute fibers (right).

\section{- Pull-Out Test}

The pull-out tests (Table 3 and Figure 11) provided information on the fiber-matrix bond for alkaline treated jute fibers with the matrices M250, M425, and M710. The debonding force $\left(\mathrm{P}_{\mathrm{a}}\right)$, the force required to disconnect the fiber from the matrix and begin the frictional phase was higher for M710 1.35 N (0.31) versus $0.73 \mathrm{~N}(0.26)$ and $0.92 \mathrm{~N}(0.34)$ for M425 and M250, respectively, suggesting the higher chemical fibermatrix bond for the matrix with higher sand particle size. The latter is confirmed by the higher chemical bond energy needed to disconnect the fiber from the matrix $\left(\mathrm{G}_{\mathrm{d}}\right)$, $49 \mathrm{~J} / \mathrm{m}^{2}$ (4) for matrix M710 while it was 41 (9) and 13(5) for the M425 and M250, 
respectively. In addition, the matrix $\mathrm{M} 710$ presented higher maximum frictional bond strength $0.52 \mathrm{MPa}(0.22)$ than the $\mathrm{M} 425$ and $\mathrm{M} 250$, that presented $0.48 \mathrm{MPa}(0.13)$ and $0.47 \mathrm{MPa}(0.10)$, respectively.

Table 3: Summary of the results of pull-out test for alkaline jute fibers with the matrices M250, M425 and M710.

\begin{tabular}{cc|ccc|c|c|c|c|c}
\hline \multirow{2}{*}{ Matriz } & $\begin{array}{c}\mathbf{l}_{\mathbf{f}} \\
(\mathbf{m m})\end{array}$ & $\begin{array}{c}\text { Área } \\
\left(\boldsymbol{\mu m}^{2}\right)\end{array}$ & $\begin{array}{c}\text { Perímetro } \\
(\boldsymbol{\mu m})\end{array}$ & $\begin{array}{c}\mathbf{P}_{\mathbf{a}} \\
(\mathbf{N})\end{array}$ & $\begin{array}{c}\mathbf{P}_{\mathbf{b}} \\
(\mathbf{N})\end{array}$ & $\begin{array}{c}\mathbf{P}_{\text {máx }} \\
(\mathbf{N})\end{array}$ & $\begin{array}{c}\mathbf{G}_{\mathbf{d}} \\
\left(\mathbf{J} / \mathbf{m}^{2}\right)\end{array}$ & $\begin{array}{l}\boldsymbol{\tau}_{\mathbf{m a ́ x}} \\
(\mathbf{M P a})\end{array}$ \\
\hline \multirow{2}{*}{ M250 } & \multirow{2}{*}{7} & 4391 & 280 & 0.92 & 0.50 & 0.93 & 13 & 0.47 \\
& & $(1067)$ & $(46)$ & $(0.34)$ & $(0.17)$ & $(0.33)$ & $(5)$ & $(0.10)$ \\
\multirow{3}{*}{ M425 } & \multirow{2}{*}{7} & 4385 & 260 & 0.73 & 0.28 & 0.84 & 41 & 0.48 \\
& & $(828)$ & $(90)$ & $(0.26)$ & $(0.19)$ & $(0.25)$ & $(9)$ & $(0.13)$ \\
M710 & \multirow{2}{*}{7} & 3139 & 232 & 1.35 & 0.88 & 1.46 & 49 & 0.52 \\
& & $(1045)$ & $(37)$ & $(0.31)$ & $(0.57)$ & $(0.31)$ & $(4)$ & $(0.22)$ \\
\hline
\end{tabular}
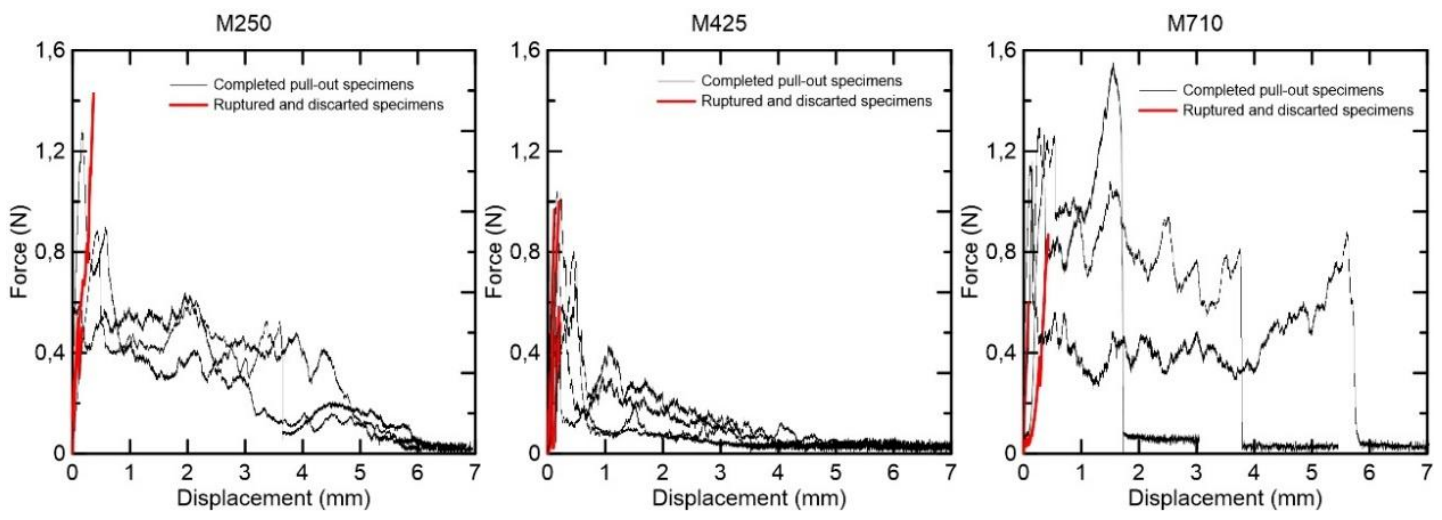

Figure 11: Pull-out test results for the matrices M250 (left), M425 (midle) and M710 (right).

\section{CONCLUSIONS}

From the results, the alkaline treatment improved the mechanical properties of the fibers improving the tensile strength $689 \mathrm{MPa}$ (74) versus $244 \mathrm{MPa}$ (95) for untreated fibers, and the elasticity modulus $35 \mathrm{GPa}(10)$ versus $22 \mathrm{GPa}(7)$ for untreatred fibers. That result is associated to the removal of the extractives and impurities that distributed in the interfibrilar region of the fibers after the treatment.

After alkaline treatment, as the fibers become more capable of rearranging over the tensile arrows, since the region is interfibrilar is less dense and all rigid due to removal of hemicellulose. 
As from the pull-out results it is remarkable that for the matrix with the bigger sand size the chemical bond energy needed to disconnect the fiber from the matrix is bigger than to the matrix with smaller sand size. In addition, the same behavior occurred for the value of the maximum frictional bond strength for the matrix with bigger sand size. The results obtained in this study showed that for the matrix with the biggest sand size (M710) studied, the chemical bond and the frictional bond strength was so great that promoted the fiber rupture before the pullout test complete. On the contrary, for the others matrix (M425 and M250) the pull-out tests were completed for the majority of the specimens tested. In conclusion, it is possible to affirm that the matrix produced with larger sand particle allowed a better interaction fiber-matrix.

\section{REFERENCES}

[1] Singh, B., Gupta, M., Tarannum, H., Randhawa, A., 2011, "Natural Fiber- Based Composite Building Materials", in Cellulose Fibers: Bio and Nano Polymer Composites - Green Chemistry and Technology. Springer-Verlag. Edited by KALIA, S., KAITH, B. S., KAUR, I.

[2] Graupner, N., Müssig, J., 2010, “Technical Applications of Natural Fibres: An Overview", in Industrial Applications of Natural Fibres: Structure, Properties and Technical Applications. 1 ed., Wiley Series in Renewable Resources. Edited by JÖRG MÜSSIG.

[3] Rahman, S., 2010, “Jute - A Versatile Natural Fibre: Cultivation, Extraction and Processing”, in Industrial Applications of Natural Fibres: Structure, Properties and Technical Applications. 1 ed., Wiley Series in Renewable Resources. Edited by JÖRG MÜSSIG.

[4] Winklerprins, A. M. G. A., 2006, "Jute Cultivation in the Lower Amazon, 19401990: An Ethnographic Account from Santarém, Pará, Brazil”, Journal of Historical Geography, v. 32, n. 4, pp. 818-838.

[5] Thomas, S., Paul, S. A., Pothan, L. A., Deepa, B., "Natural Fibres: Structure, Properties and Applications", in Cellulose Fibers: Bio and Nano Polymer Composites - Green Chemistry and Technology. Springer-Verlag. Edited by Kalia, S., Kaith, B. S., Kaur, I, (2011).

[6] Fidelis, M.E.A., Desenvolvimento e Caracterização Mecânica de Compósitos Cimentícios Têxteis Reforçados com Fibras de Juta. PhD thesis, Federal University of Rio de Janeiro, (2014).

[7] Ferreira, S.R, Effect of surface treatments on the structure, mechanical, durability and bond behavior of vegetable fibers for cementitious composites. $\mathrm{PhD}$ thesis, Federal University of Rio de Janeiro, (2016).

[8] Magalhães, M. S., Caracterização Experimental de Compositos Cimentícios reforçados com fibras de PVA: Processo de fratura, propriedades térmicas, deformações diferidas e estabilidade térmica. Tese de D.Sc., COPPE/UFRJ, Rio de Janeiro, RJ, Brasil, 2010.

[9] Arbelaiz A, Fernández B, Ramos Ja, Mondragon I. "Thermal and crystallization 
studies of short flax fibre reinforced polypropylene matrix composites: effect of treatments", Thermochimica Acta. pp. 111-121, 2006.

[10] ASTM.C1557 /2014 - Standard Test Method for Tensile Sntrength and Young's Modulus of Fibers. West Conshohocken, PA, USA: American Society for Testing and Materials.

[11] Dweck, J.; Büchler, P.M.; Cartledge, F.K., "The effect of different bentonites on cement hydration during solidification/stabilization of tannery wastes, Journal of Thermal Analysis and Calorimetry, Vol.64, pp. 1011-1016, 2001.

\section{ACKOWLEDGEMENTS}

The authors gratefully acknowledge the "Conselho Nacional de Desenvolvimento Científico e Tecnológico”, CNPq, (Brazilian National Science Foundation), for financial support for this work. 